University for Business and Technology in Kosovo

UBT Knowledge Center

Oct 27th, 3:15 PM - 4:45 PM

\title{
The moving object reflected under Matlab test-bench (Simulation model through buit-in functions)
}

\author{
Virtyt Lesha \\ Luarasi University, virtyt.lesha@gmail.com \\ Jozef Bushati \\ University of Shkodra, jozef.bushati@gmail.com \\ Dea Strica \\ University of Tirana, deastrica@hotmail.com
}

Follow this and additional works at: https://knowledgecenter.ubt-uni.net/conference

Part of the Computer Sciences Commons, and the Digital Communications and Networking Commons

\section{Recommended Citation}

Lesha, Virtyt; Bushati, Jozef; and Strica, Dea, "The moving object reflected under Matlab test-bench (Simulation model through buit-in functions)" (2018). UBT International Conference. 113.

https://knowledgecenter.ubt-uni.net/conference/2018/all-events/113

This Event is brought to you for free and open access by the Publication and Journals at UBT Knowledge Center. It has been accepted for inclusion in UBT International Conference by an authorized administrator of UBT Knowledge Center. For more information, please contact knowledge.center@ubt-uni.net. 


\title{
The moving object reflected under Matlab test-bench (Simulation model through buit-in functions)
}

\author{
Virtyt Lesha ${ }^{1}$, Jozef Bushati ${ }^{2}$, Dea Strica ${ }^{3}$ \\ 1 "Luarasi” University, Rruga e Elbasanit, Tirana, Albania 2 \\ University of Shkodra, Sheshi "2 Prilli”, Shkodra, Albania \\ ${ }_{3}$ University of Tirana, Sheshi "Nene Tereza",Tirana, Albania \\ virtyt.lesha@gmail.com ${ }^{1}$ jozef.bushati@gmail.com ${ }^{2}$ deastrica@ hotmail.com $^{3}$
}

Digital image processing is an area that finds many applications in three-dimensional graphics. One of the subjects considered in image processing is detection of moving objects.

In this paper, we have analyzed the performance of an algorithm that detects a moving object. The performance relates to the speed of moving object during a pre-determined time interval.

The methodology supports Matlab integrated with built-in functions. Specifically, as input of the simulation model is a video material containing moving objects. The model reads a video file presenting moving objects; after the model is executed in Matlab, the output emits moving objects associated to selections moving accordingly with moving objects.

The performance analysis consists on tracking the people/objects from the colored markers as accurately as possible. This simulation serve for further research that lead to the generation of a practical product of detecting movable objects.

Keywords: object, individual, performance, algorithm

\section{Introduction}

The field of study of computer vision is a space of space that offers considerable challenges in the digital image processing and digital processing of video for research purposes and the development of concrete applications such as: biometric processing, applications in civil and military security cameras, etc.

Numerous studies and research have been conducted in recent years in this field of study in general and in object tracking in particular. Object tracking itself explores a series of discussions and debates about simulation models and related simulation simulations used and the advantages and disadvantages associated with each model and simulation software in particular.The approach of fuzzy logic modeling is widely applied to such patterns and a series of simulations have been developed for research purposes in connection with the further fading of such techniques. The Matlab program is a closed- source modeling and simulation softaware that enables many simulation spaces that preserve inter alia the field of study of digital signal processing in general and its derivatives in particular.

In our study, we introduced effects on the performance of an improved algorithmic model that detects the movement of an object in a video file. The modified algorithm consists in creating a 
model based on fuzzy logic methods to reduce the time it takes for the Matlab program's ability to track the moving object in the video.

Concretely, in our simulation model we have taken into account a video file that has a duration of 62 seconds which represents an environment that has in its content people moving.

The performance of an object tracking is calculated at the time of separation between the sealing sequences of objects and the time the color marker needs to go after the object in question. The smaller it is this time, the more continuous and qualitative the tracking of the object in question. In this sense, the standard algorithm requires more time than the improved algorithm according to the fuzzy approach; this means that the object's moving object is slower in pursuit of the object and requires a lot of time to go after it and this is an anomaly especially for objects that are at high speeds.

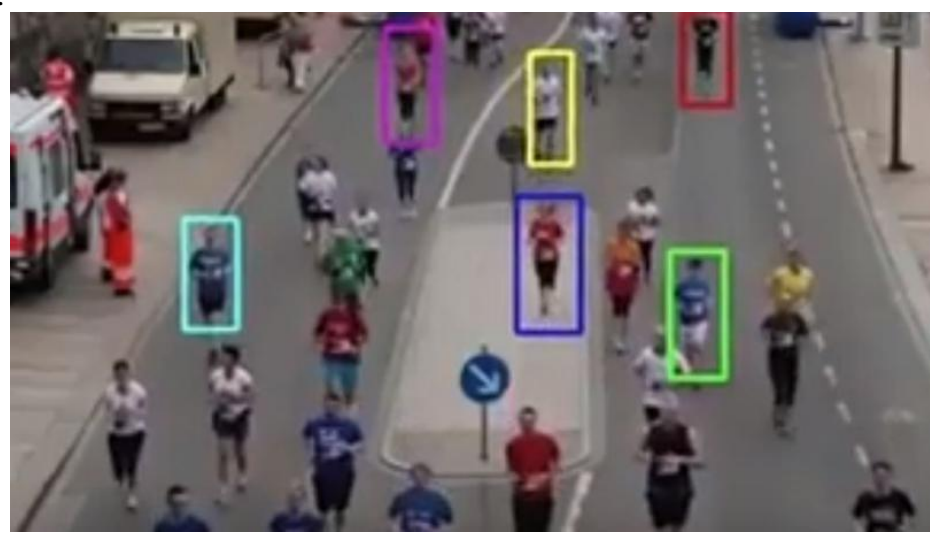

Fig. 1. View the results of object tracking in the video file used in our simulation model

As a performance element, statistical methods that are modeled and developed through Matlab are given which give a quantitative sense of the trend and the transfer of the time values necessary for the marker to follow the object in motion.

Finally, part of this research also includes the issues of the recommendations and limits that this fuzzy modification of object tracking modifies.

\section{Methodology}

The methodology used in this research consists of data sampling and statistical treatment of data. Specifically, in our simulation model is used a video file that contains backgrounds of objects and persons in motion. This video file has a duration of 62 seconds. The essence of improved algorithm performance consists in interfering with a cycle of this algorithm and adding two additional variables that lead to the growth of the algorithm complex, but which itself improve the performance in question.

The application of this interference, in the minimization of time, is the color marking shown in Figure 1, to follow the moving object in question.

The smaller the time it takes for trackers to track the object in motion, the higher the performance of the simulation model. 
In our analysis of the performance, 120 samples were taken under the effect of the statistical analysis; these samples consist of the recent moments of the unit of time; moreover, for each of the samples is measured the necessary time each marker needs to track the object in motion for that moment; the unit of this time is taken into consideration in millisecond units. Where the analysis process is applied as in the case of a standard algorithm approached by fuzzy concepts as well as in the improved algorithm case.

Further, for the calculation of performance, statistical analyzes were taken by creating simulated trend-lines through Matlab R2017a. The applied trendline algorithm is "smoothing spline", reflecting the resulting data of this trend-line both in the case of standard and improved method. The "smoothing" parameter used is the default value of 0.9999977182557248 which is approximately 1 . Also, part of the simulation results and the spline smoothing statistic is also the activation of the residual concept presentation option.

\section{Results}

The simulation model results are shown in the following two figures. Figure 2 shows the trend line through the "smooth spline" of the standard algorithm performance. As can be seen, values in milliseconds do not exceed $3.2 \mathrm{~ms}$ while in figure 3 it is noted that the value of the tracking time of the moving object does not exceed 2.5 milliseconds. Also parallel to the curve fitting through spox spots are also shown residual plots results.

Additional data on statistical simulation results are shown below:

a) Standard algorithm:

Smoothing spline:

$f(x)=$ piecewise polynomial computed from $p$ where $x$ is normalized by mean 63.5 and std 36.52

Smoothing parameter $\mathrm{p}=0.99999772$

Goodness of fit:

SSE: 0.5591

$R$-squared 0.764

Adjusted R-square: 0.4108

RMSE: 0.1057

b) Improved algorithm:

Smoothing spline:

$\mathrm{f}(\mathrm{x})=$ piecewise polynomial computed from $\mathrm{p}$ where $\mathrm{x}$ is normalized by mean 63.5 and std 36.52

Smoothing parameter $\mathrm{p}=0.99999772$

Goodness of fit:

SSE: 0.3249

R-squared 0.7341

Adjusted R-square: 0.336

RMSE: 0.8057 


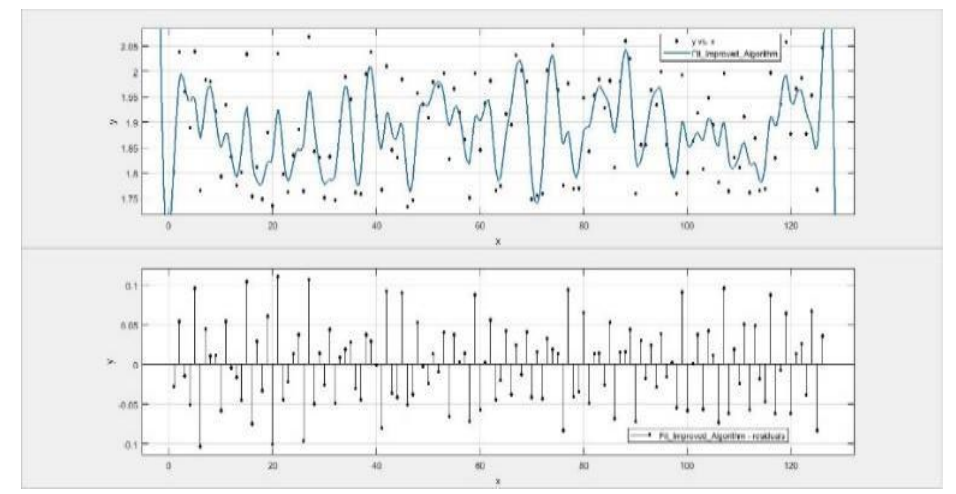

Fig. 2. Results of statistical simulation for the standard algorithm

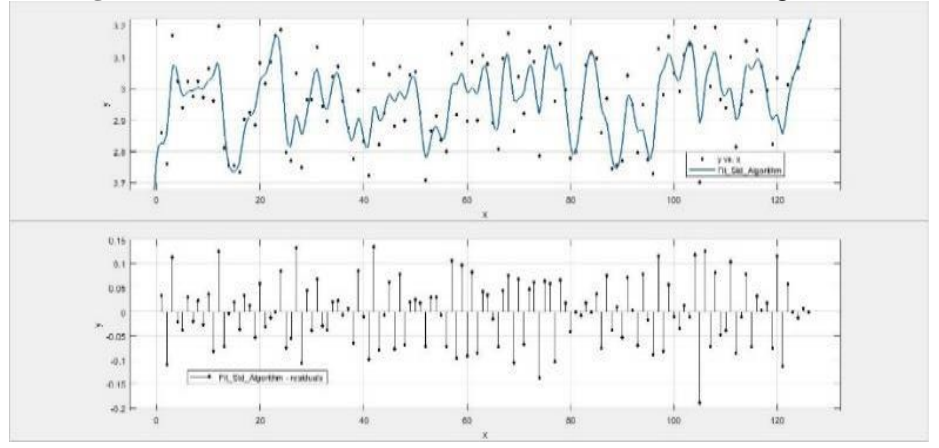

Fig. 3. Results of statistical simulation for improved algorithm

\section{Conclusions}

In this paper, we discussed the object tracking issue under the simulation optics by the fuzzy logic approach by considering improving the performance of this algorithm.

The process of this study consisted in obtaining 120 sample sequences from a video file that has backgrounds in the background.

The purpose of this study consisted in the performance analysis in the sense of tracking more and more of the object moving into the video file thus leading to the linearity and quality of the algorithm.

Improvement of the simulation model performance is also reflected in the statistical analysis by the smooth spline method and therefore the expected results.

As is also the case with simulation results, the time difference value for the improved algorithm is smaller than in the case of a standard algorithm,

Finally, part of the search is the fact of further limitations and suggestions that include the simulation model in question. These limits consist in the further reduction of the time required to track the objects in motion that leads to higher performance quality and this is more noticeable when the objects in motion are at relatively high speeds. 


\section{References}

1. Attaway, S. (2013). MATLAB: A practical introduction to programming and problem solving. Amsterdam: Elsevier, B/H, Butterworth-Heinemann.

2. Attaway, S. (2017). MATLAB: A practical introduction to programming and problem solving. Amsterdam: Elsevier/Butterworth-Heinemann.

3. Challa, S. (2011). Fundamentals of object tracking. Cambridge: Cambridge University Press.

4. Chityala, R., \& Pudipeddi, S. (2014). Image processing and acquisition using Python. Boca Raton: Chapman \& Hall/CRC.

5. El-Halym, H. A., Mahmoud, I. I., \& Habib, S. E. (2013). Particle filters for object tracking: Enhanced algorithm and efficient implementations. Saarbrü cken: LAP Lambert Academic Publishing.

6. Gonzalez, R. C., \& Woods, R. E. (2014). Digital image processing. New Delhi: Dorling Kindersley.

7. Gonzalez, R. C., \& Woods, R. E. (2018). Digital image processing. New York: Pearson.

8. Martinez, W. L., \& Cho, M. J. (2015). Statistics in MATLAB: A primer. Boca Raton: CRC Press.

9. Martinez, W. L., \& Martinez, A. R. (2016). Computational statistics handbook with MATLAB. Boca Raton: CRC Press, Taylor \& Francis Group.

10. Martinez, W. L. (2017). Exploratory data analysis with matlab. Place of publication not identified: Chapman \& Hall Crc.

11 .

12. Nguyen, H. T., \& Walker, E. (2006). A first course in fuzzy logic. Boca Raton: Chapman \& Hall/CRC

13. Nixon, M. S., \& Aguado, A. S. (2012). Feature extraction \& image processing for computer vision. Oxford: Academic Press.

14. Petrou, M., \& Petrou, C. (2015). Image processing: The fundamentals. Chichester: John Wiley and Sons.

15. Ross, T. J. (2017). Fuzzy logic with engineering applications. Southern Gate, Chichester, West Sussex, United Kingdom: Wiley.

16. Russ, J. C., \& Neal, F. B. (2016). The image processing handbook. Boca Raton: CRC Press, Taylor \& Francis Group.

17. Solomon, C., \& Breckon, T. (2012). Fundamentals of digital image processing: A practical approach with examples in Matlab. Chichester: Wiley-Blackwell.

18. Tanaka, K. (1997). An introduction to fuzzy logic for practical applications. New York: Springer. 